\title{
Abnormalities in the Distributed Network of Sustained Attention Predict Neuroleptic Treatment Response in Schizophrenia
}

\author{
Robert M. Cohen, Ph.D., M.D., Thomas E. Nordahl, Ph.D., M.D., William E. Semple, Ph.D.,
} Paul Andreason, M.D., and David Pickar, M.D.

The regional cerebral metabolic rates of 19 male medicationwithdrawn schizophrenic patients were determined by positron emission tomography (PET) while performing an auditory discrimination task (CPT). Regardless of the accuracy of their CPT performance, the schizophrenic patients had lower metabolic rates in their prefrontal cortex and higher rates in their posterior putamen compared to 41 healthy males. Abnormally low right anterior midprefrontal cortex metabolic rates predicted better clinical response while high basal ganglia rates and low mid-cingulate rates predicted poor treatment response to neuroleptics. The findings imply that the sustained attention pathway and its distributed network of brain structures are likely to play an important role in the expression of psychotic symptoms and the mediation of their response to antipsychotics.

[Neuropsychopharmacology 19:36-47, 1998]

Published by Elsevier Science Inc.
KEY WORDS: Striatum; Frontal cortex; Thalamus; Deoxyglucose; Cerebral metabolic rates; Positron emission tomography

Failure to execute goal-directed behavior is a prominent manifestation of schizophrenia. Sustained attention on continuous performance tasks (CPT) has served as a laboratory model of this failure in positron emission tomography (PET) studies of regional glucose metabolic rates (Cohen et al. 1988a). In PET studies (Buchsbaum et al. 1990, 1992a; Cohen et al. 1987), medication-withdrawn and neuroleptic-naive patients with schizophre-

From the Section on Clinical Brain Imaging, Laboratory of Cerebral Metabolism, National Institute of Mental Health and Experimental Therapeutics Branch, National Institute of Mental Health, Bethesda, MD. T.E.N. is now at the University of California Medical Center, Davis, CA. W.E.S. is now at the University Hospital of Cleveland, Cleveland, $\mathrm{OH}$.

Address correspondence to: Robert M. Cohen, Ph.D., M.D., Laboratory of Cerebral Metabolism, NIMH, NIH, Bldg. 36, Room 1A05, 36 Convent Dr. MSC 4030, Bethesda, MD, 20892-4030.

Received April 16, 1997; revised October 27, 1997; accepted October 30, 1997. nia performing $\mathrm{CPT}$, and in our study, regardless of performance and medication status, were found to have abnormally low functional activity of the midprefrontal cortex area that served as the biological determinant of this task in normal controls (Cohen et al. 1987, 1988c, 1992). These studies, although consistent with earlier data from a variety of methods on the importance of the right prefrontal cortex in attentional processes (Mesulam 1981), and subsequent and concurrent other PET studies utilizing cerebral blood flow as a measure of activation (Posner and Petersen 1990), were all performed at low resolutions and most, if not all, with calculated attenuation corrections.

Using a tomograph with improved resolution, and one in which an empirically determined attenuation correction could be used, was expected to lead to more accurate localized metabolic rate determinations, particularly for brain regions small in size and located in the inferior parts of the brain, e.g., subcortex. This expectation was borne out in a new study of normal controls performing CPT (Cohen et al. 1992) that provided evidence of basal ganglia involvement in the task per- 
formance of normal controls that had previously gone undetected. The new findings were consistent with earlier animal and human studies of basal ganglia involvement in attentional processes (see Mesulam, 1981 and Cohen et al., 1992 for references). The importance of this finding for understanding the phenotypic expression of schizophrenia attained greater significance as a result of the findings of Buchsbaum and his colleagues (Buchsbaum et al. 1992a). These investigators not only found diminished basal ganglia metabolism in addition to diminished frontal cortex metabolism in patients never medicated before with neuroleptics, but also that lower subcortical metabolic rates, prior to neuroleptic treatment, predicted a favorable clinical response to haloperidol (Buchsbaum et al. 1992c) and clozapine (Buchsbaum et al. 1992b). Since neuroleptics increase basal ganglia metabolic rates (Cohen et al. 1988b, 1997; DeLisi et al. 1985), the above basal ganglia findings suggest that neuroleptics exert a normalizing metabolic effect on the basal ganglia and by inference on its functional activity in neuroleptic responsive schizophrenics.

The following PET scan study in neuroleptic resistant patients with schizophrenia was undertaken to: 1) Replicate our previous findings of a decrease in functional activity of the prefrontal cortex in schizophrenia with special reference to the possibility that poor CPT performance is the cause of the diminished prefrontal cortex activity; 2) Determine if reduced functional activity of this region during CPT is associated with more negative symptoms at the time of scan as suggested by the work of Wolkin et al. (1992) and Tamminga et al. (1992); 3) Compare with a higher resolution tomograph the functional activity of the basal ganglia of schizophrenic patients to that of normal controls, and if found to differ, evaluate whether basal ganglia activity is related to patient symptoms at the time of their scan; and 4) replicate Buchsbaum et al. (1992a, b) findings of pretreatment left caudate, right posterior putamen, thalamus, and hippocampal functional activity as predictors of neuroleptic treatment response while conducting an exploratory analysis of the predictiveness of CPT performance itself and the functional activities of those other brain regions that act as biological determinants of this performance, the right midprefrontal cortex and mid-cingulate.

\section{MATERIALS AND METHODS}

\section{Subjects}

Forty-one male normal controls (aged $31.4 \pm 8.6$ years) and 19 male schizophrenic patients (aged $32.6 \pm 6.2$ years) participated in the study after giving informed consent. Each normal volunteer was interviewed by a psychiatrist, received a physical examination, completed an MMPI, and submitted blood and urine sam- ples for routine laboratory evaluation. On the basis of all the available information, volunteers were proscribed from participating if they had any serious medical illness, any history of significant mental (DSM-III-R criteria) or neurologic disorder, or first-degree relatives with histories consistent with DSM-III-R diagnoses of schizophrenia, major mood disorder, or alcohol abuse. All patients were given a modified SADS and met DSMIII-R criteria for schizophrenia based on the evaluation of two psychiatrists. Patients were excluded if a significant medical or neurological problem was present. The patients were residing on a research unit at the $\mathrm{NIH}$ at the time of scan and throughout treatment, and were the same patients previously reported in Pickar et al. 1992 and Cohen et al. 1997.

Within two weeks of admission, subjects were begun on "blind" medication regimens and neuroleptics were converted to the typical neuroleptic fluphenazine hydrochloride. The dose of fluphenazine was titrated clinically and maintained for at least four weeks. Placebo substitution was made after varying periods of continuous fluphenazine treatment, both to maintain the blind treatment protocol and to limit the number of drug-free patients on the ward at one time. All patients were maintained on a regimen of placebo for at least 2.5 weeks. It was during this time that the "pre-treatment" scans were obtained. At the completion of the placebo period, clozapine treatment was begun.

Patient symptoms were measured using the BunneyHamburg Rating Scale for psychosis (BHRS-P) (Bunney and Hamburg 1963), the Brief Psychiatric Rating Scale (BPRS) (Overall and Gorham, 1961), and the Scale for the Assessment of Negative Symptoms (SANS) (Andreasen 1984). The average BHRS-P was $7.50 \pm 2.63$, the total BPRS was $64.5 \pm 19.6$, and the SANS was $68.7 \pm$ 21.2 for the medication-withdrawn patients who had not received neuroleptics for an average of $19.9 \pm 4.7$ days (range 13-31 days) prior to scan. Age at onset was $18.6 \pm 5.43$ years and duration of illness $13.2 \pm 8.94$ years. Number of hospitalizations prior to stay at $\mathrm{NIH}$ was $6.53 \pm 5.71$. A detailed description of the patient populations and their clinical and biologic responses to fluphenazine and clozapine treatment has been reported (Pickar et al. 1992). Changes in patient ratings were based on the differences between ratings obtained during the 5th and 6th weeks following the initiation of neuroleptic treatment in comparison to those obtained during the week that the patient was scanned while receiving placebo.

\section{PET Scan Procedure}

Subjects, with eyes patched, began their auditory discrimination task several minutes prior to the injection of 4 to $5 \mathrm{mCi}$ of $\left[{ }^{18} \mathrm{~F}\right] \mathrm{FDG}$ and completed the task $30 \mathrm{~min}-$ utes after injection. The auditory discrimination task in 
which subjects must identify one of three auditory tones was described in detail elsewhere (Cohen et al. 1988c). In brief, scanning, beginning $30 \mathrm{~min}$ after isotope injection, was performed on a Scanditronix (Essex, Mass) PET scanner with a 5-6 mm full-width-half-maximum in-plane resolution and a $z$ axis resolution of 11.8 $\mathrm{mm}$. A transmission scan was used to calculate attenuation and the tracer input curve was calculated from blood samples obtained from the radial artery. Four sets of seven planes were obtained for each subject starting at $5 \mathrm{~mm}$ above the plane parallel to the canthomeatal line $(\mathrm{CM})$. The interslice interval was approximately $3.5 \mathrm{~mm}$.

\section{Data Analysis}

CPT Performance. The CPT performance measures obtained directly were those of hits (HITS, the number of targets correctly identified) and false alarms (FA, the number of distractors incorrectly identified as targets). An accuracy measure LNCPT, calculated as $\ln$ [HITS/ $(\mathrm{FA}+1)]$, is used to correct for subject response bias. LNCPT is highly correlated to the more usual modeldependent signal analysis parameter $d^{\prime}$ (Cohen et al. 1992), and has been demonstrated to correlate with right midprefrontal cortex activity (Cohen et al. 1992), and to be sensitive to a neuropsychiatric disorder with attention abnormalities (Matochik et al. 1996) as well as a drug known to affect attention processes (Cohen et al. 1994). Because of technical difficulties, CPT response records were only recoverable for 34 of the normal controls and 14 of the schizophrenic patients limiting the number of subjects that could be used in these analyses relating to CPT performance.

Based on the performance of the normal controls, the schizophrenic patients were divided into two subgroups, a group of subjects with LNCPT measures that were greater than 1 standard deviation below the mean of the normal controls (LOW, $\mathrm{n}=8$ ), and a second group ( $\mathrm{HIGH}, \mathrm{n}=6$ ) of more accurately performing schizophrenic patients, those performing at better than or equal to 1 standard deviation below the mean of the normal controls. As intended, the LOW subgroup tended toward fewer HITS (LOW $=85.9 \pm 69.7$, HIGH $=$ $136.5 \pm 32.8, t=1.64, p=.13$ ) and more FA (LOW = $35.3 \pm 46.1, \mathrm{HIGH}=5.33 \pm 4.08, t=1.57, p=.14)$ and performed significantly less accurately (LNCPT: LOW $=$ $1.14 \pm 1.37, \mathrm{HIGH}=3.26 \pm 0.73, t=3.40, p<.006)$ than the HIGH subgroup. LNCPT of HIGH was not statistically different from that of the NC $(t=0.52, p=\mathrm{NS})$. Although the specific method that was used to subdivide the schizophrenic patients based on their performance was arbitrary, a variety of different subdividing schemes were tried, including those based on splitting the sample into two equal halves from poorest to highest performers, and another schema in which only the four most accurately performing patients with schizophrenia comprised the HIGH subgroup. All of the methods examined gave results which did not differ in substance from that which is reported in the manuscript.

Regional Metabolic Data. Raw pixel values were converted to glucose metabolic rates in $\mu$ moles of glucose per $100 \mathrm{~g}$ of tissue per minute by means of previously reported kinetic constants (Brooks 1982; Phelps et al. 1979; Sokoloff et al. 1977). To extract regional glucose metabolic rates, 60 rectangular boxes were located in five standard planes (plane A, $94 \mathrm{~mm}$ above $\mathrm{CM}$ line; plane $\mathrm{B}, 81 \mathrm{~mm}$ above $\mathrm{CM}$ line; plane $\mathrm{C}, 67 \mathrm{~mm}$ above $\mathrm{CM}$ line; plane $\mathrm{D}, 53 \mathrm{~mm}$ above $\mathrm{CM}$ line; and plane $\mathrm{E}, 40$ $\mathrm{mm}$ above CM line) chosen from one of the four sevenplane scan sets (Cohen et al. 1988c, 1992; Semple et al. 1993) (Figure 1). The location and size of the regions of interest (ROIs) on the transverse planes have been previously illustrated (Andreason et al. 1994). Global gray glucose metabolic rate, an estimate of the average gray matter-rich glucose metabolic rate was determined by averaging the glucose metabolic rates obtained from all the gray matter-rich areas of the cortex sampled in Planes B-E (an adequate match for Plane A could not be found in a few subjects). Normalized regional glucose metabolic rate, the localized metabolic measure used in all the statistical analyses, was obtained by dividing the absolute regional metabolic rate for a ROI by the global gray glucose metabolic rate. Anatomical structures were judged as contained within ROIs according to the human brain atlas of Matsui and Hirano (Matsui and Hirano 1978).

\section{Statistical Analysis}

Because we had only observed abnormalities in normalized and not absolute global regional metabolic rates in patients with schizophrenia in prior studies, only normalized regional metabolic rates are examined in the current study. Regional absolute metabolic rates are highly correlated with global glucose metabolic rates whereas the use of normalized metabolic rates minimizes the contribution of the global metabolic rate to regional rates (Clark et al. 1984). To reduce the likelihood of a Type 1 error in the metabolic rate comparisons of 60 regions in the schizophrenic patients compared to the normal controls, we chose to use multivariate analyses and to examine only regions in which there were a priori reasons for doing so. The prefrontal cortex was examined based on our earlier findings (Cohen et al. 1987) that the metabolic rates of prefrontal cortex regions of interest, but not regions of interest in the pre-motor or orbital frontal cortex were reduced in the schizophrenic patients. When the prefrontal cortex is referred to in the text in the comparison between groups, it is the mean of 


\section{Left and Medial}

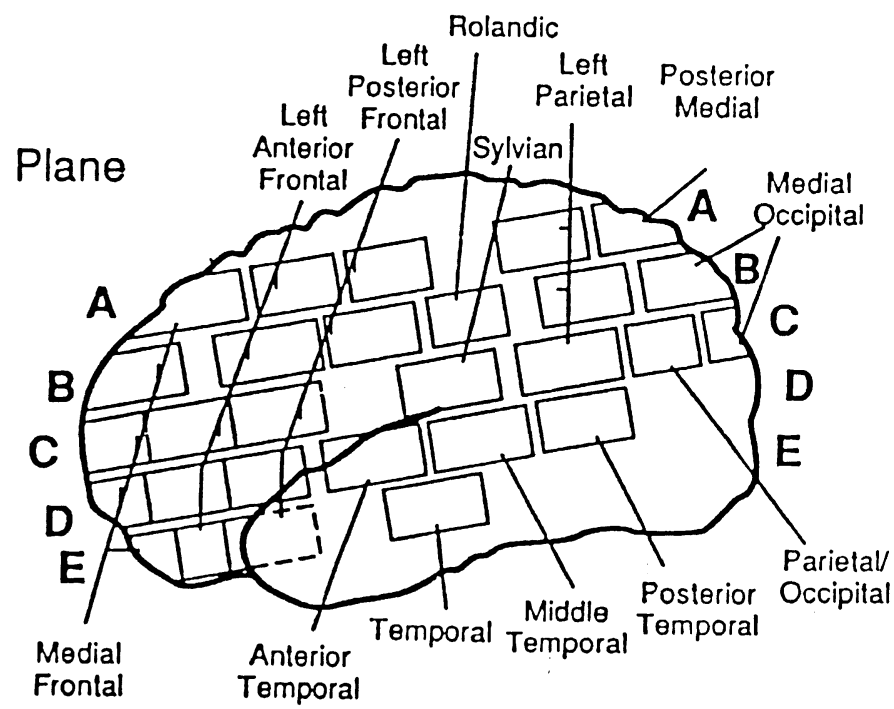

Right

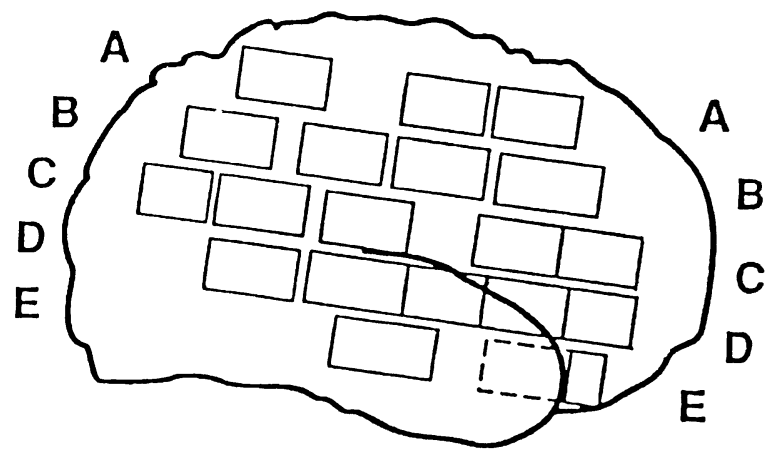

Figure 1. Schematic representation of regions sampled in the left and right hemispheres (Left and Medial, Right) is shown. Regions labeled as Medial, although sampled from the medial portion of the cortex, are represented where possible asincomplete boxes on the lateral surface. The boxes outlined by dashed lines are sampled from the surface of the frontal cortex medial to the temporal lobe.

the left and right anterior and posterior ROIs of the frontal cortex in Planes B, C, and D. The basal ganglia was also examined for differences because of the reports of both abnormally high and abnormally low metabolic rates in schizophrenia (Buchsbaum et al. 1992a; Early et al. 1987; Resnick et al. 1988; Wolkin et al. 1985). When the multivariate analyses were significant, student $t$-tests were performed to localize the findings.

Because of the arbitrariness of classifying subjects as responders or non-responders, predictors of treatment response were examined initially by product-moment correlations between regional metabolic rates and changes in behavior ratings. To limit the possibility of Type I error, the correlations were restricted to the two regions of the basal ganglia, left caudate and right posterior putamen, as well as the thalamus and hippocampus, all previously reported by Buchsbaum and his colleagues (Buchsbaum et al. 1992c) to be treatment response predictors, and to the two other brain regions that have been determined to be important biological determinants of CPT, the right anterior frontal cortex region of Plane C (CRAF, also referred to as the right anterior midprefrontal cortex) and the mid-cingulate (Cohen et al. 1988c, 1992, 1994; Matochik et al. 1996).

One disadvantage of the correlation approach is the inability to specify whether it is the 'responders' or the 'non-responders' who actually have abnormal metabolic rates. To determine this, subgroups need to be defined and group comparisons performed. Based on the sug- gestion of Kane et al. (1988) to use the criterion of a $20 \%$ reduction in BPRS in treatment resistant schizophrenic patients to define treatment response to clozapine, our patient group was divided into responders $(R)$ and nonresponders (NR) with respect to their fluphenazine and clozapine treatment trials. An initial multivariate analysis of the same six regions evaluated by correlation analysis was performed to determine if responders and non-responders to fluphenazine and clozapine differed. Because the numbers in these subgroups were small, and only data that was consistent with the correlational data would be interpreted as significant, we decided to perform student $t$-tests to localize changes if a $p<.1$ was found in the multivariate analysis.

Finally, although comparisons are made between clozapine and fluphenazine, it is of considerable importance to note that all patients who were scanned in both the fluphenazine- and clozapine-treatment states were treated first with fluphenazine. Thus, we cannot exclude the possibility that any differences we observed relate primarily to time rather than the selective effect of either antipsychotic.

\section{RESULTS}

As expected from our earlier data (Cohen et al. 1987, 1988b), the regional normalized metabolic rates of the prefrontal cortex of this new group of medication-with- 
drawn patients with schizophrenia (Pickar et al. 1992; Cohen et al. 1997) were found to be lower than that of the normal controls $(\mathrm{NC}=1.051 \pm 0.020, \mathrm{SZ}=1.017 \pm$ $0.040, t=4.33, d f=58, p<.0001,2$-tailed). A multivariate analysis of the entire frontal cortex by Plane and subsequent univariate analyses of individual regions confirmed differences in Planes B, C, and D of both left and right hemispheres, but not in Planes $\mathrm{A}$ (premotor cortex) and E (orbital frontal cortex) (see Table 1). For example, CRAF (the right anterior frontal cortex ROI of Plane C), the region most closely associated with CPT performance in normal controls was $4.6 \%$ lower in the schizophrenic patients in the current study compared to $4.9 \%$ in our previous study.

The multivariate analysis of the ROIs of the basal ganglia revealed a significant difference between the schizophrenic patients and normal controls that was localized to the posterior putamen (see Table 1).

\section{Effect of CPT Performance on Regional Metabolic Differences}

As expected for the CPT, the schizophrenic patients (SZ) performed less accurately than the normal controls (LNCPT: $\mathrm{SZ}=2.11 \pm 1.54, \mathrm{NC}=3.51 \pm 1.14, t=3.4, p=$ .002 ; HITS: $(\mathrm{SZ}=107.6 \pm 60.9, \mathrm{NC}=180.9 \pm 31.3, t=$ $5.52, p<.0001 ; \mathrm{FA}: \mathrm{SZ}=22.4 \pm 37.3, \mathrm{NC}=10.1 \pm 22.4$, $t=1.41, p=\mathrm{NS})$. To examine the possibility, as we did in our earlier study, whether or not the lower prefrontal cortex metabolic rate observed in schizophrenic patients could be attributed to their poor CPT performance, the patients were divided into the two subgroups of HIGH $(\mathrm{n}=6)$ and LOW performing patients $(n=8)$ (see Materials and Methods). The prefrontal cor- tex metabolic rate of LOW $(1.026 \pm 0.049)$ and HIGH $(1.008 \pm 0.023)$ patients did not differ. The absence of difference was also observed for the right anterior frontal cortex ROI in Plane C (CRAF: LOW $=1.019 \pm 0.046$, $\mathrm{HIGH}=1.006 \pm 0.105)$, the region to which performance accuracy localizes to in normals (Cohen et al. 1987, 1992). The absence of a prefrontal cortex difference between the two subgroups suggests that the diminished prefrontal cortical metabolic rates of the schizophrenic patients do not simply derive from their poor CPT performance. This conclusion was strengthened by the finding that the multivariate analysis of the frontal cortex comparing the HIGH and LOW subgroups was not significant, $T^{2}=2.68, F(5,7)=0.34, p=$ NS whereas that comparing the normal controls and the HIGH subgroup was significant, $T^{2}=37.7, F(5,41)=$ $6.87, p<.0001$. Finally, there was no significant correlation between CRAF and LNCPT $(r=0.18, \mathrm{NS})$ in the schizophrenic patients.

The subgroup analysis indicated that it was unlikely that the poor performance of the schizophrenic patients contributed to their abnormally high putamen metabolic rates. Although, the multivariate analysis of HIGH vs. LOW subgroups for the regions comprising the basal ganglia revealed a $T^{2}=33.89, F(6,7)=3.30, p<.07$, the univariate tests were significant only for higher metabolic rates in the right caudate $(\mathrm{LOW}=1.061 \pm 0.106$, $\mathrm{HIGH}=0.944 \pm 0.075, t=2.29, p=.04)$ and left anterior putamen $(\mathrm{LOW}=1.13 \pm 0.122, \mathrm{HIGH}=0.994 \pm$ $0.100, t=2.22, p<.05)$, not in the posterior putamen of the LOW subgroup, the region found to differ in the schizophrenia, normal control comparison. Further, the multivariate analysis of the basal ganglia of HIGH vs. normal controls was significant $T^{2}=25.56, F(6,40)=$

Table 1. Multivariate Analysis of Normalized Metabolic Rates of Schizophrenic Patients Compared to Normal Controls: Means (s.d.)

\begin{tabular}{|c|c|c|c|c|c|}
\hline & $\begin{array}{l}\text { Controls } \\
(\mathrm{n}=41)\end{array}$ & $\begin{array}{l}\text { Patients } \\
(\mathrm{n}=19)\end{array}$ & $\begin{array}{c}\% \\
\text { NC-PTS }\end{array}$ & $t$-Value & $p$ Value \\
\hline \multicolumn{2}{|c|}{$\begin{array}{c}\text { Frontal cortex by Plane } \\
\text { Hotelling's } T^{* *} 2=29.8, F(5,53)=5.55, p<.0004\end{array}$} & \multicolumn{4}{|c|}{ Frontal cortex by Plane } \\
\hline \multicolumn{6}{|l|}{ Frontal cortex } \\
\hline A Plane (94 mm above CM line) & $1.045(0.056)$ & $1.026(0.067)$ & $1.9 \%$ & 1.18 & NS \\
\hline B Plane (84 mm above CM line) & $1.066(0.036)$ & $1.026(0.077)$ & $3.8 \%$ & 2.72 & $<.009$ \\
\hline C Plane (67 $\mathrm{mm}$ above CM line) & $1.062(0.043)$ & $1.026(0.041)$ & $3.5 \%$ & 3.01 & $<.004$ \\
\hline D Plane (53 mm above CM line) & $1.025(0.031)$ & $0.999(0.045)$ & $2.6 \%$ & 2.55 & $<.02$ \\
\hline E Plane (40 $\mathrm{mm}$ above $\mathrm{CM}$ line) & $0.989(0.055)$ & $1.007(0.043)$ & $-1.8 \%$ & -1.28 & NS \\
\hline \multicolumn{6}{|c|}{ Basal ganglia } \\
\hline Brain region & & & & & \\
\hline L caudate & $1.011(0.098)$ & $1.006(0.123)$ & $0.6 \%$ & 0.19 & NS \\
\hline R Caudate & $0.989(0.097)$ & $1.005(0.097)$ & $-1.7 \%$ & -0.61 & NS \\
\hline $\mathrm{L}$ ant putamen & $1.065(0.126)$ & $1.060(0.124)$ & $0.5 \%$ & 0.14 & NS \\
\hline $\mathrm{R}$ ant putamen & $1.009(0.105)$ & $1.021(0.152)$ & $-1.2 \%$ & -0.35 & NS \\
\hline L post putamen & $0.946(0.103)$ & $1.047(0.122)$ & $-10.6 \%$ & -3.32 & $<.002$ \\
\hline $\mathrm{R}$ post putamen & $0.933(0.097)$ & $1.008(0.121)$ & $-8.0 \%$ & -2.57 & $<.02$ \\
\hline
\end{tabular}


Table 2. Product-Moment Correlations with Respect to Symptom Ratings in Medication-Withdrawn Patients at Time of Pet Scan $(n=19)$

\begin{tabular}{|c|c|c|c|c|c|c|}
\hline & \multicolumn{2}{|c|}{ BHRS-P } & \multicolumn{2}{|c|}{ BPRS } & \multicolumn{2}{|c|}{ SANS } \\
\hline & $r$ & $p$ Value & $r$ & $p$ Value & $r$ & $p$ Value \\
\hline L caudate & -0.31 & NS & -0.43 & $<.07$ & -0.38 & $<.11$ \\
\hline $\mathrm{R}$ post putamen & -0.54 & $<.02$ & -0.51 & $<.03$ & -0.34 & NS \\
\hline Cingulate & -0.01 & NS & 0.12 & NS & -0.07 & NS \\
\hline Hippocampus & -0.33 & NS & -0.48 & $<.04$ & -0.31 & NS \\
\hline Thalamus & -0.32 & NS & -0.30 & NS & -0.12 & NS \\
\hline CRAF & -0.38 & $<.12$ & -0.43 & $<.07$ & -0.53 & $<.03$ \\
\hline $\begin{array}{l}\text { LNCPT } \\
\quad(\mathrm{n}=13)\end{array}$ & -0.49 & $<.10$ & -0.30 & NS & -0.22 & NS \\
\hline
\end{tabular}

3.79, $p<.005$ with the univariate analyses of left (SZ $=$ $1.04 \pm 0.091, \mathrm{NC}=0.946 \pm 0.103, t=2.1, p=.04)$ and right $(\mathrm{SZ}=1.050 \pm 0.147, \mathrm{NC}=0.933 \pm 0.097, t=2.59$, $p<.02)$ posterior putamen ROIs significantly different as was the case for the total group of schizophrenics.

\section{Regression Analysis of Functional Activities in the Sustained Attention Network and Schizophrenic Symptoms (Table 2)}

Lower pre-treatment right posterior putamen and hippocampal metabolic rates were significantly associated with higher pre-treatment BPRS symptom ratings. CRAF showed a similar trend with respect to BPRS ratings and a significant effect with respect to SANS.

\section{Predictors of Neuroleptic Response (Tables 3 and 4)}

Lower pre-treatment left caudate, right posterior putamen, right anterior midprefrontal cortex, and higher mid-cingulate functional activities were associated with better treatment response to neuroleptics. Poor CPT performance also appeared to predict better treatment response, but the data failed to reach statistical significance, perhaps because of the reduced number of subjects for which CPT data was available (fluphenazine, 12; clozapine, 8). Although the number of significant correlations with behavioral measures of change were greater for clozapine than fluphenazine, this could in part be attributed to the patient sample differences (see Table 4 where only subjects who were treated with both fluphenazine and clozapine are included) and the order of treatment. As noted in the Materials and Methods, patients were first treated with fluphenazine, then withdrawn from medications during a placebo period in which the "pre-treatment" scan was obtained, and then placed on clozapine. Moreover, no single clozapine response correlation was significantly different from that observed for fluphenazine response.

Table 3. Product-Moment Correlations of Pre-Treatment Normalized Regional Metabolic Rates with Changes in Symptom Ratings Following 5-6 Weeks of Fluphenazine and Clozapine Treatment

\begin{tabular}{|c|c|c|c|c|c|c|c|c|c|c|c|c|}
\hline & \multicolumn{12}{|c|}{ Changes in Symptom Ratings } \\
\hline & \multicolumn{6}{|c|}{ FLU $(n=18)$} & \multicolumn{6}{|c|}{ CLOZ $(n=14)$} \\
\hline & \multicolumn{2}{|c|}{ BHRS-P } & \multicolumn{2}{|c|}{ BPRS } & \multicolumn{2}{|c|}{ SANS } & \multicolumn{2}{|c|}{ BHRS-P } & \multicolumn{2}{|c|}{ BPRS } & \multicolumn{2}{|c|}{ SANS } \\
\hline & ABS & $\%$ & ABS & $\%$ & ABS & $\%$ & ABS & $\%$ & ABS & $\%$ & ABS & $\%$ \\
\hline L Caudate & $\begin{array}{l}-0.47 \\
(<.05)\end{array}$ & $\begin{array}{l}-0.36 \\
(<.15)\end{array}$ & $\begin{array}{l}-0.37 \\
(<.12)\end{array}$ & $\begin{array}{c}-0.35 \\
(\mathrm{NS})\end{array}$ & $\begin{array}{c}-0.29 \\
(\mathrm{NS})\end{array}$ & $\begin{array}{c}-0.21 \\
(\mathrm{NS})\end{array}$ & $\begin{array}{c}-0.36 \\
(\mathrm{NS})\end{array}$ & $\begin{array}{c}-0.29 \\
(\mathrm{NS})\end{array}$ & $\begin{array}{l}-0.53 \\
(=.05)\end{array}$ & $\begin{array}{l}-0.56 \\
(<.04)\end{array}$ & $\begin{array}{c}-0.40 \\
(\mathrm{NS})\end{array}$ & $\begin{array}{c}-0.35 \\
\text { (NS) }\end{array}$ \\
\hline R post putamen & $\begin{array}{l}-0.36 \\
(<.14)\end{array}$ & $\begin{array}{l}-0.26 \\
(\mathrm{NS})\end{array}$ & $\begin{array}{l}-0.41 \\
(<.09)\end{array}$ & $\begin{array}{c}-0.33 \\
(\mathrm{NS})\end{array}$ & $\begin{array}{l}-0.26 \\
(\mathrm{NS})\end{array}$ & $\begin{array}{c}-0.21 \\
(\mathrm{NS})\end{array}$ & $\begin{array}{c}-0.57 \\
(.04)\end{array}$ & $\begin{array}{l}-0.45 \\
(<.11)\end{array}$ & $\begin{array}{l}-0.65 \\
(<.02)\end{array}$ & $\begin{array}{l}-0.64 \\
(<.02)\end{array}$ & $\begin{array}{l}-0.55 \\
(<.05)\end{array}$ & $\begin{array}{l}-0.50 \\
(<.07)\end{array}$ \\
\hline Cingulate & $\begin{array}{c}0.04 \\
(\mathrm{NS})\end{array}$ & $\begin{array}{l}0.03 \\
\text { (NS) }\end{array}$ & $\begin{array}{c}0.27 \\
(\mathrm{NS})\end{array}$ & $\begin{array}{c}0.26 \\
(\mathrm{NS})\end{array}$ & $\begin{array}{c}0.25 \\
(\mathrm{NS})\end{array}$ & $\begin{array}{c}0.20 \\
(\mathrm{NS})\end{array}$ & $\begin{array}{r}0.45 \\
(<.11)\end{array}$ & $\begin{array}{r}0.45 \\
(<.11)\end{array}$ & $\begin{array}{r}0.49 \\
(<.08)\end{array}$ & $\begin{array}{r}0.54 \\
(<.05)\end{array}$ & $\begin{array}{r}0.65 \\
(<.02)\end{array}$ & $\begin{array}{r}0.60 \\
(<.03)\end{array}$ \\
\hline Hippocampus & $\begin{array}{c}-0.17 \\
(\mathrm{NS})\end{array}$ & $\begin{array}{c}-0.10 \\
(\mathrm{NS})\end{array}$ & $\begin{array}{c}-0.24 \\
(\mathrm{NS})\end{array}$ & $\begin{array}{c}-0.21 \\
(\mathrm{NS})\end{array}$ & $\begin{array}{c}-0.22 \\
(\mathrm{NS})\end{array}$ & $\begin{array}{c}-0.16 \\
(\mathrm{NS})\end{array}$ & $\begin{array}{c}-0.16 \\
(\mathrm{NS})\end{array}$ & $\begin{array}{c}-0.06 \\
(\mathrm{NS})\end{array}$ & $\begin{array}{l}-0.47 \\
(<.09)\end{array}$ & $\begin{array}{l}-0.25 \\
\text { (NS) }\end{array}$ & $\begin{array}{c}-0.17 \\
(\mathrm{NS})\end{array}$ & $\begin{array}{l}0.04 \\
(\mathrm{NS})\end{array}$ \\
\hline Thalamus & $\begin{array}{l}-0.38 \\
(<.12)\end{array}$ & $\begin{array}{c}-0.29 \\
\text { (NS) }\end{array}$ & $\begin{array}{l}-0.36 \\
(<.15)\end{array}$ & $\begin{array}{c}-0.29 \\
(\mathrm{NS})\end{array}$ & $\begin{array}{c}-0.19 \\
\text { (NS) }\end{array}$ & $\begin{array}{c}-0.09 \\
\text { (NS) }\end{array}$ & $\begin{array}{l}0.14 \\
\text { (NS) }\end{array}$ & $\begin{array}{c}0.35 \\
(\mathrm{NS})\end{array}$ & $\begin{array}{c}-0.04 \\
(\mathrm{NS})\end{array}$ & $\begin{array}{c}0.11 \\
(\mathrm{NS})\end{array}$ & $\begin{array}{l}0.13 \\
\text { (NS) }\end{array}$ & $\begin{array}{c}0.22 \\
\text { (NS) }\end{array}$ \\
\hline CRAF & $\begin{array}{l}-0.55 \\
(<.02)\end{array}$ & $\begin{array}{c}-0.61 \\
(=.007)\end{array}$ & $\begin{array}{c}-0.39 \\
(\mathrm{NS})\end{array}$ & $\begin{array}{l}-0.37 \\
(<.13)\end{array}$ & $\begin{array}{c}-0.26 \\
(\mathrm{NS})\end{array}$ & $\begin{array}{c}-0.11 \\
(\mathrm{NS})\end{array}$ & $\begin{array}{l}-0.65 \\
(<.02)\end{array}$ & $\begin{array}{l}-0.76 \\
(.002)\end{array}$ & $\begin{array}{l}-0.49 \\
(<.08)\end{array}$ & $\begin{array}{l}-0.63 \\
(<.02)\end{array}$ & $\begin{array}{l}-0.58 \\
(<.04)\end{array}$ & $\begin{array}{l}-0.72 \\
(.004)\end{array}$ \\
\hline LNCPT & $\begin{array}{l}-0.48 \\
(<.12)\end{array}$ & $\begin{array}{c}-0.40 \\
\text { (NS) }\end{array}$ & $\begin{array}{l}-0.49 \\
(<.11)\end{array}$ & $\begin{array}{l}-0.45 \\
(<.11)\end{array}$ & $\begin{array}{l}-0.49 \\
(<.11)\end{array}$ & $\begin{array}{c}-0.36 \\
(\mathrm{NS})\end{array}$ & $\begin{array}{c}-0.55 \\
\text { (NS) }\end{array}$ & $\begin{array}{c}-0.46 \\
\text { (NS) }\end{array}$ & $\begin{array}{c}-0.47 \\
(\mathrm{NS})\end{array}$ & $\begin{array}{c}-0.42 \\
\text { (NS) }\end{array}$ & $\begin{array}{c}-0.40 \\
\text { (NS) }\end{array}$ & $\begin{array}{c}-0.42 \\
\text { (NS) }\end{array}$ \\
\hline
\end{tabular}

Product moment correlations between symptom ratings scales (BHRS-P, Bunney-Hamburg Rating Scale; BPRS, Brief Psychiatric Rating Scale; and SANS, Scale for the Assessment of Negative Symptoms) and pretreatment normalized metabolic rates of brain regions considered part of the substrata of sustained attention (CRAF, the right anterior prefrontal cortex ROI of Plane C). Correlations are listed as $r$ values for both the actual change scores (ABS) and percentage change from time of scan (\%). $p$ values are listed in parentheses immediately below $r$ values. The subject numbers for each analysis are as listed except for LNCPT, a measure of CPT accuracy, in which there were only 12 subjects in the fluphenazine group and eight subjects in the clozapine group. Although $p$ values were considered significant only if $<.05$, we elected to show all $p$ values $<.15$. 
Table 4. Product-Moment Correlations of Pre-treatment Normalized Regional Metabolic Rates with Changes in Symptom Ratings Following 5-6 Weeks of Fluphenazine and Clozapine Treatment in the 13 Patients that Received Both Treatments

\begin{tabular}{|c|c|c|c|c|c|c|c|c|c|c|c|c|}
\hline & \multicolumn{12}{|c|}{ Changes in Symptom Ratings } \\
\hline & \multicolumn{6}{|c|}{ FLU } & \multicolumn{6}{|c|}{ CLOZ } \\
\hline & \multicolumn{2}{|c|}{ BHRS-P } & \multicolumn{2}{|c|}{ BPRS } & \multicolumn{2}{|c|}{ SANS } & \multicolumn{2}{|c|}{ BHRS-P } & \multicolumn{2}{|c|}{ BPRS } & \multicolumn{2}{|c|}{ SANS } \\
\hline & ABS & $\%$ & ABS & $\%$ & ABS & $\%$ & ABS & $\%$ & ABS & $\%$ & ABS & $\%$ \\
\hline L caudate & $\begin{array}{l}-0.56 \\
(<.05)\end{array}$ & $\begin{array}{l}-0.61 \\
(<.03)\end{array}$ & $\begin{array}{c}-0.41 \\
(\mathrm{NS})\end{array}$ & $\begin{array}{c}-0.42 \\
\text { (NS) }\end{array}$ & $\begin{array}{l}-0.47 \\
(<.11)\end{array}$ & $\begin{array}{l}-0.46 \\
(<.12)\end{array}$ & $\begin{array}{l}-0.50 \\
(<.09)\end{array}$ & $\begin{array}{l}-0.49 \\
(<.09)\end{array}$ & $\begin{array}{l}-0.63 \\
(<.03)\end{array}$ & $\begin{array}{c}-0.69 \\
(=.009)\end{array}$ & $\begin{array}{l}-0.46 \\
(<.12)\end{array}$ & $\begin{array}{l}-0.44 \\
(=.13)\end{array}$ \\
\hline $\mathrm{R}$ post putamen & $\begin{array}{c}-0.33 \\
(\mathrm{NS})\end{array}$ & $\begin{array}{c}-0.28 \\
(\mathrm{NS})\end{array}$ & $\begin{array}{c}-0.34 \\
(\mathrm{NS})\end{array}$ & $\begin{array}{c}-0.26 \\
(\mathrm{NS})\end{array}$ & $\begin{array}{c}-0.18 \\
\text { (NS) }\end{array}$ & $\begin{array}{c}-0.11 \\
\text { (NS) }\end{array}$ & $\begin{array}{l}-0.64 \\
(<.02)\end{array}$ & $\begin{array}{l}-0.55 \\
(<.06)\end{array}$ & $\begin{array}{l}-0.68 \\
(=.01)\end{array}$ & $\begin{array}{c}-0.70 \\
(=.008)\end{array}$ & $\begin{array}{l}-0.56 \\
(<.05)\end{array}$ & $\begin{array}{l}-0.53 \\
(<.07)\end{array}$ \\
\hline Cingulate & $\begin{array}{c}0.32 \\
(\mathrm{NS})\end{array}$ & $\begin{array}{c}0.37 \\
(\mathrm{NS})\end{array}$ & $\begin{array}{r}0.51 \\
(<.08)\end{array}$ & $\begin{array}{r}0.52 \\
(<.07)\end{array}$ & $\begin{array}{c}0.42 \\
(\mathrm{NS})\end{array}$ & $\begin{array}{c}0.40 \\
\text { (NS) }\end{array}$ & $\begin{array}{r}0.57 \\
(<.05)\end{array}$ & $\begin{array}{r}0.65 \\
(<.02)\end{array}$ & $\begin{array}{r}0.55 \\
(<.05)\end{array}$ & $\begin{array}{r}0.63 \\
(<.03)\end{array}$ & $\begin{array}{c}0.71 \\
(=.007)\end{array}$ & $\begin{array}{c}0.69 \\
(=.009)\end{array}$ \\
\hline Hippocampus & $\begin{array}{c}-0.05 \\
(\mathrm{NS})\end{array}$ & $\begin{array}{c}-0.03 \\
(\mathrm{NS})\end{array}$ & $\begin{array}{c}-0.14 \\
(\mathrm{NS})\end{array}$ & $\begin{array}{c}-0.10 \\
\text { (NS) }\end{array}$ & $\begin{array}{c}-0.26 \\
(\mathrm{NS})\end{array}$ & $\begin{array}{c}-0.18 \\
(\mathrm{NS})\end{array}$ & $\begin{array}{c}-0.23 \\
(\mathrm{NS})\end{array}$ & $\begin{array}{c}0.02 \\
(\mathrm{NS})\end{array}$ & $\begin{array}{l}-0.53 \\
(<.07)\end{array}$ & $\begin{array}{c}-0.31 \\
(\mathrm{NS})\end{array}$ & $\begin{array}{c}-0.20 \\
\text { (NS) }\end{array}$ & $\begin{array}{l}0.01 \\
\text { (NS) }\end{array}$ \\
\hline Thalamus & $\begin{array}{c}-0.27 \\
(\mathrm{NS})\end{array}$ & $\begin{array}{c}-0.16 \\
(\mathrm{NS})\end{array}$ & $\begin{array}{c}-0.31 \\
(\mathrm{NS})\end{array}$ & $\begin{array}{c}-0.23 \\
(\mathrm{NS})\end{array}$ & $\begin{array}{c}-0.26 \\
(\mathrm{NS})\end{array}$ & $\begin{array}{c}-0.24 \\
(\mathrm{NS})\end{array}$ & $\begin{array}{c}0.05 \\
\text { (NS) }\end{array}$ & $\begin{array}{c}0.29 \\
(\mathrm{NS})\end{array}$ & $\begin{array}{c}-0.12 \\
(\mathrm{NS})\end{array}$ & $\begin{array}{c}0.03 \\
(\mathrm{NS})\end{array}$ & $\begin{array}{c}0.08 \\
(\mathrm{NS})\end{array}$ & $\begin{array}{c}0.16 \\
\text { (NS) }\end{array}$ \\
\hline CRAF & $\begin{array}{l}-0.51 \\
(<.08)\end{array}$ & $\begin{array}{l}-0.58 \\
(<.04)\end{array}$ & $\begin{array}{c}-0.34 \\
(\mathrm{NS})\end{array}$ & $\begin{array}{c}-0.34 \\
(\mathrm{NS})\end{array}$ & $\begin{array}{c}-0.29 \\
(\mathrm{NS})\end{array}$ & $\begin{array}{c}-0.25 \\
(\mathrm{NS})\end{array}$ & $\begin{array}{l}-0.50 \\
(<.09)\end{array}$ & $\begin{array}{l}-0.59 \\
(<.04)\end{array}$ & $\begin{array}{c}-0.38 \\
\text { (NS) }\end{array}$ & $\begin{array}{l}-0.52 \\
(<.07)\end{array}$ & $\begin{array}{l}-0.57 \\
(<.05)\end{array}$ & $\begin{array}{l}-0.67 \\
(<.02)\end{array}$ \\
\hline $\begin{array}{l}\text { LNCPT } \\
\quad(n=7)\end{array}$ & $\begin{array}{c}-0.52 \\
(\mathrm{NS})\end{array}$ & $\begin{array}{c}-0.42 \\
(\mathrm{NS})\end{array}$ & $\begin{array}{c}-0.59 \\
(\mathrm{NS})\end{array}$ & $\begin{array}{c}-0.55 \\
(\mathrm{NS})\end{array}$ & $\begin{array}{l}-0.63 \\
(<.14)\end{array}$ & $\begin{array}{l}-0.63 \\
(<.14)\end{array}$ & $\begin{array}{l}-0.40 \\
\text { (NS) }\end{array}$ & $\begin{array}{c}-0.23 \\
(\mathrm{NS})\end{array}$ & $\begin{array}{c}-0.36 \\
\text { (NS) }\end{array}$ & $\begin{array}{c}-0.28 \\
\text { (NS) }\end{array}$ & $\begin{array}{c}-0.34 \\
(\mathrm{NS})\end{array}$ & $\begin{array}{c}-0.29 \\
(\mathrm{NS})\end{array}$ \\
\hline
\end{tabular}

This is essentially the same table as Table 3 except that ony those patients that had completed both fluphenazine and clozapine treatment trials are included.

The unexpected high number of correlations, although supportive of the sensitivity of the metabolic rate of regions of the brain involved in CPT performance in relation to clozapine treatment response, raised the question of specificity. Therefore, the remaining 60 regions of interest were evaluated for their informativeness to predict percentage change in BPRS in response to clozapine. Not a single additional significant correlation was observed (data not shown).

Subgrouping by Treatment Response. To facilitate the interpretation of associations between pre-treatment localized brain activities and treatment response, comparisons were made between responder and non-responder subgroups and the normal controls for the same six regions considered part of the biological substratum of sustained attention by multivariate analysis. The Hotelling's $T^{2}$ for the comparison of responders to nonresponders for fluphenazine was $23.08(F(6,11)=2.64, p<$ $.08)$ and for clozapine was $93.50(\mathrm{~F}(6,7)=9.09, p=$ $.005)$. Student $t$-tests were performed to localize and quantify the direction of the differences between the responders and non-responders, the results of which are tabulated in Table 5. In addition, Table 5 lists the results of $t$-tests performed to compare the response patient subgroups and the normal controls for the primary purpose of describing in which response subgroup the abnormality appears to be when differences between responders and non-responders were found.
Consistent with the association data, an abnormally high right posterior putamen metabolic rate was found in neuroleptic non-responders, whereas there was a trend for higher left caudate metabolic rates in nonresponders compared to responders. While not apparent in the correlation analyses, thalamic activity was lower in fluphenazine responders than in non-responders. The latter findings agree with the data of Buchsbaum et al. (1992a, b) who also evaluated response by subgroups, although his classification schema was different than the current one.

Abnormally low CRAF was found in the neuroleptic responders subgroups, whereas an abnormally low mid-cingulate activity was observed in the clozapinetreatment nonresponders subgroup. To place the CRAF findings in perspective, we examined all of the remaining members of the original 60 ROIs obtained for each subject. CRAF was the only region to demonstrate a statistically significant difference, by $t$-test, between the clozapine-treatment responders and non-responders subgroups.

\section{DISCUSSION}

An important goal of imaging studies of schizophrenia is to identify regions or neuroanatomical pathways either responsible for the behavioral phenotype or that 
Table 5. Comparison of Pre-Treatment Normalized Regional Metabolic Rates of Fluphenazine and Clozapine Responders Compared to Non-Responders

\begin{tabular}{|c|c|c|c|c|c|c|c|c|c|c|c|}
\hline & & & & & & & \multicolumn{5}{|c|}{ Comparison to NC } \\
\hline & \multirow{2}{*}{\multicolumn{3}{|c|}{ FLU }} & \multirow{2}{*}{\multicolumn{3}{|c|}{ CLOZ }} & \multicolumn{5}{|c|}{$p$ Values } \\
\hline & & & & & & & \multirow[b]{2}{*}{$\begin{array}{c}\text { Mean (SD) } \\
(\mathrm{n}=41)\end{array}$} & \multicolumn{2}{|c|}{ FLU } & \multicolumn{2}{|c|}{ CLOZ } \\
\hline & $\begin{array}{c}R \\
(n=7)\end{array}$ & $\begin{array}{c}\text { NR } \\
(n=11)\end{array}$ & $p$ value & $\begin{array}{c}\mathbf{R} \\
(\mathrm{n}=7)\end{array}$ & $\begin{array}{c}\text { NR } \\
(n=7)\end{array}$ & $p$ value & & NC vs. $R$ & NC vs. NR & NC vs. R & NC vs. NR \\
\hline L caudate & $\begin{array}{c}0.944 \\
(0.085)\end{array}$ & $\begin{array}{c}1.050 \\
(0.133)\end{array}$ & .08 & $\begin{array}{c}0.952 \\
(0.084)\end{array}$ & $\begin{array}{c}1.081 \\
(0.152)\end{array}$ & .07 & $\begin{array}{c}1.011 \\
(0.098)\end{array}$ & $<.10$ & NS & $<.14$ & $<.12$ \\
\hline $\mathrm{R}$ post putamen & $\begin{array}{c}0.920 \\
(0.095)\end{array}$ & $\begin{array}{c}1.061 \\
(0.111)\end{array}$ & $<.02$ & $\begin{array}{c}0.963 \\
(0.126)\end{array}$ & $\begin{array}{c}1.085 \\
(0.087)\end{array}$ & $<.06$ & $\begin{array}{c}0.933 \\
(0.097)\end{array}$ & NS & $<.001$ & NS & $<.001$ \\
\hline Cingulate & $\begin{array}{c}0.957 \\
(0.109)\end{array}$ & $\begin{array}{c}0.948 \\
(0.133)\end{array}$ & NS & $\begin{array}{c}1.014 \\
(0.071)\end{array}$ & $\begin{array}{c}0.899 \\
(0.137)\end{array}$ & .07 & $\begin{array}{c}0.979 \\
(0.075)\end{array}$ & NS & NS & NS & $<.03$ \\
\hline Hippocampus & $\begin{array}{c}0.739 \\
(0.078)\end{array}$ & $\begin{array}{c}0.799 \\
(0.087)\end{array}$ & NS & $\begin{array}{c}0.788 \\
(0.104)\end{array}$ & $\begin{array}{c}0.808 \\
(0.041)\end{array}$ & NS & $\begin{array}{c}0.750 \\
(0.045)\end{array}$ & NS & $<.02$ & $<.11$ & $<.003$ \\
\hline Thalamus & $\begin{array}{c}0.903 \\
(0.081)\end{array}$ & $\begin{array}{c}1.011 \\
(0.115)\end{array}$ & $<.05$ & $\begin{array}{c}0.956 \\
(0.098)\end{array}$ & $\begin{array}{c}0.978 \\
(0.138)\end{array}$ & NS & $\begin{array}{c}0.983 \\
(0.119)\end{array}$ & $<.10$ & NS & NS & NS \\
\hline CRAF & $\begin{array}{c}0.978 \\
(0.044)\end{array}$ & $\begin{array}{c}1.010 \\
(0.060)\end{array}$ & NS & $\begin{array}{c}0.963 \\
(0.037)\end{array}$ & $\begin{array}{c}1.051 \\
(0.078)\end{array}$ & $<.02$ & $\begin{array}{c}1.054 \\
(0.075)\end{array}$ & $<.02$ & NS & .003 & NS \\
\hline LNCPT & $\begin{array}{l}1.47 \\
(1.51)\end{array}$ & $\begin{array}{c}2.19 \\
(1.51)\end{array}$ & NS & $\begin{array}{c}0.98 \\
(2.43)\end{array}$ & $\begin{array}{c}2.15 \\
(1.89)\end{array}$ & NS & $\begin{array}{c}3.51 \\
(1.14)\end{array}$ & $<.003$ & $<.009$ & $<.005$ & .02 \\
\hline
\end{tabular}

Means of normalized metabolic rates are listed with standard deviations in parentheses immediately below the means for each region considered part of the substrata of sustained attention for fluphenazine (FLU) and clozapine (CLOZ) responders (R) and non-responders (NR) subgroups. Responders were defined as having obtained a $20 \%$ or greater drop in their Brief Psychiatric Rating Scale score after 5-6 weeks of neuroleptic treatment. The number of subjects in each group is as listed except for the analysis of LNCPT, a measure of CPT accuracy. Number of subjects for LNCPT were four and eight for fluphenazine R and NR respectively, and two and six for clozapine R and NR, respectively. Although $p$ values were considered significant only if $<.05$, we elected to show all $p$ values $<.15$.

act as mediators of clinical response. However, imaging studies inferring regional functional activities from regional metabolic rates or cerebral blood flow determinations are dynamically dependent upon what the brain is engaged in doing and, thus, have meaning only in this context. While there are benefits, therefore, to simplifying this context to facilitate the interpretation of these measurements, there are also potential pitfalls as the context may preclude the likelihood of studying just those pathways that may be abnormal in schizophrenia (Weinberger et al. 1986).

The behavioral constraints we chose remain a compromise. Although the CPT may be deemed a complex task, it is one of the simplest complex tasks that schizophrenic patients and individuals at risk for schizophrenia have been reliably determined to perform abnormally (Erlenmeyer-Kimling and Cornblatt 1987; Nuechterlein 1991; Nuechterlein et al. 1994). An added benefit of the manner of the current experimental design with respect to schizophrenia and functional activity measures, is that it emphasizes aspects of sustained attention over other cognitive elements such as sensory and motor processes. Moreover, the contributions to functional activation of random behavior that a patient may engage in intermittently during the task are likely to be aver- aged out because of the thirty minutes during which the metabolic measurement is made.

Having found apparent abnormalities in the prefrontal cortex of patients with schizophrenia, we were faced with the problem of distinguishing whether the differences in regional activation patterns were the biological determinants of the differences in cognitive phenotype or whether the poor performance of the patients was the cause of the differences in regional activation patterns, i.e., the "chicken and egg" problem (Cohen et al. 1986). One solution that has been suggested to avoid this problem is to find tasks in which schizophrenic patients perform normally, but in which they demonstrate different activation patterns (Cohen et al. 1986; Levy 1996). However, assuming one could identify such a task, results from functional imaging studies of schizophrenic patients performing this task, would still be subject to ambiguity because of the inherent difficulty of demonstrating that patients and controls use the same cognitive strategy to perform the task (Cohen et al. 1986).

The inference we derived from our earlier data, and for which the current data remain consistent with, is that the lower prefrontal cortex values in the medication-withdrawn patients with schizophrenia cannot pri- 
marily be attributed to the failure of these patients to perform the CPT as well as the normal controls. First, the prefrontal cortex area that shows diminution of functional activity is much greater than that which shows a metabolic response to the tasks in normal subjects (Cohen et al. 1987, 1988c, 1992). For example, only the right prefrontal cortex of Plane $\mathrm{C}$ is found to have higher metabolic rates in normal subjects performing the CPT compared to "resting" normal subjects whereas the schizophrenic patients have diminished activity in both the left and right prefrontal hemispheres of Planes, B, C, and D. Second, those patients with schizophrenia who performed within a standard deviation of the mean of the normal controls were as affected or more affected than the poorest performing patients. This is observed both by the analysis of the subgroups where patients are classified on the basis of performance, and by the absence of correlations between performance accuracy and prefrontal cortex activity.

Under identical conditions, we have also measured regional functional activities in two other populations that perform the CPT very poorly, patients with Thyroid Resistance Disorder (Matochik et al. 1996), and normal subjects who have received scopolamine (Cohen et al. 1994). Both of these populations demonstrate the poor performance on the CPT is insufficient to produce the deficits observed in the prefrontal cortex of the schizophrenic patients.

In addition to the replication of the prefrontal cortex findings, the new data suggests that schizophrenic patients, while performing CPT, have abnormally high posterior putamen functional activity. The posterior putamen results, though preliminary, are consistent with some reports of striatal hyperactivity (Early et al. 1987; Resnick et al. 1988; Wolkin et al. 1985). Because of the small size of the striatum, its location in the inferior part of the brain and its responsiveness to task and performance, and possibly with symptom profile at the time of scan (Table 2) together with the differences in tomographs, task conditions, and region of interest approach that different investigators have used, it is not surprising that basal ganglia findings in schizophrenic populations have demonstrated variability (Buchsbaum 1995).

The clear implication of finding, for the second time, that the HIGH and LOW performance subgroups of the medication-withdrawn schizophrenic patients did not differ significantly in glucose metabolic rates in taskrelevant brain areas, is of an apparent uncoupling of these regions from the biological determination of this task in schizophrenia (Cohen et al. 1987, 1988a, b). A possible explanation for this uncoupling is that schizophrenic patients use different pathways from those used by normal individuals in performing the CPT because of a fundamental abnormality in this pathway for sustained attention. Structures within the basal ganglia may play some part in this second pathway, as HIGH and LOW performing subgroups differed with respect to functional activity in the right caudate and left anterior putamen. Whether the abnormality in sustained attention observed is a model for the more general failure to execute goal directed behavior in schizophrenia remains to be established.

\section{Predictors of Neuroleptic Response}

However, accepting the evidence in favor of abnormalities in the biological substrata of sustained attention in schizophrenia, the question that naturally arose was whether information about CPT performance and the functional activation of those brain regions required to perform CPT, could contribute to our understanding of the phenotype of schizophrenia including symptomatology and response to neuroleptic treatment. The current data suggests that it does.

Abnormal activities in these brain structures, e.g., the right midprefrontal cortex and posterior putamen, and poor CPT performance are found primarily in those schizophrenic patients with the highest symptom ratings at the time of scan (see Table 2). Consistent with the earlier reports of prefrontal cortical metabolic rates by Wolkin et al. (1992) and Tamminga et al. (1992), diminished activity in the right anterior midprefrontal cortex is associated with higher negative symptom ratings. The fact that these findings in schizophrenic patients scanned at rest were essentially the same as what we found in patients performing CPT during their scan is consistent with the earlier hypothesis of an uncoupling between prefrontal cortex activity and CPT performance.

Without specifically alluding to the role of these brain structures in CPT, Buchsbaum and his colleagues (Buchsbaum et al. 1992a, b) reported that diminished pre-treatment activities in the left caudate and right posterior putamen were the best predictors of clinical response to haloperidol and clozapine, whereas diminished activities of the left anterior thalamus and left hippocampal regions were somewhat less informative. Although, not always reaching statistical significance in our two-tailed tests, our results with clozapine and fluphenazine (Tables 3-5) are that those patients with lower left caudate, right posterior putamen, thalamic, and hippocampal activity during their placebo period were more likely to have better clinical responses than those with higher metabolic rates in these regions. In addition, the two other regions of the brain most closely associated with CPT performance, CRAF and the midcingulate also appear to be correlated with neuroleptic treatment response, but in opposite directions from each other as is the direction of their change in response to CPT in normals. Whereas in normal subjects performing CPT, CRAF functional activity is high, mid-cingulate activity is low. 


\section{Compensation vs. Normalization}

Since neuroleptics, in general, appear to increase striatal and thalamic relative metabolism, our data, that those patients with lower subcortical metabolic rates have the best responses to neuroleptic treatment, appears to be consistent with Buchsbaum et al.'s (Buchsbaum et al. 1992c) proposal that neuroleptics work by correcting abnormally low subcortical activity. However, before accepting this interpretation, it is important to consider additional data that bear on the issue.

First, the existing PET literature would suggest that basal ganglia metabolic rates are raised to levels of activity that are higher than normal by many neuroleptics (Cohen et al. 1997). Second, in our population, neither of these two basal ganglia regions nor the thalamus have lower than normal metabolic rates. Third, although responders to clozapine and fluphenazine in our cohort have lower than normal left caudate metabolism, they have normal right posterior putamen values, whereas non-responders have somewhat higher than normal caudate metabolic rates and clearly higher than normal right posterior putamen rates.

Thus, our data is equally consistent with neuroleptics having difficulty improving the symptoms of those patients who already have higher than normal subcortical metabolic rates. Our own working hypothesis has been that neuroleptics engender changes in regional functional activities that compensate for rather than correct schizophrenic abnormal brain activity (Cohen et al. 1997). The logical implications of the compensation hypothesis are that some symptoms of schizophrenia remain despite the adaptation engendered by neuroleptic treatment, and that compensation may occur in some patients prior to neuroleptic treatment. Conceptually, the pre-treatment and post-treatment states are most parsimoniously viewed as part of the same continuum with respect to the relationship between basal ganglia metabolic rates and symptoms. However, as with any initially linear correlation in nature, at some point the linear relationship between basal ganglia metabolic rate and symptoms would be expected to break down as a result of asymptotically approaching a ceiling effect for symptom improvement through alteration of basal ganglia functional activity. Regardless of theoretical explanation, the association of basal ganglia metabolic rates with treatment response and symptom presentation offers an explanation for the divergent subcortical findings in schizophrenia.

Notably, it was also the schizophrenic patients with the poorest $\mathrm{CPT}$ performance and the highest ratings who were the ones most responsive to neuroleptic treatment. Thus, these results, taken together, are consistent with the dual-process model of cognitive abnormality in schizophrenia proposed by Kay and Singh (1979) and the similar proposals of others to explain the findings that neuro- leptics improved only some of the cognitive abnormalities associated with schizophrenia. Applying this model to the current data, the neuroleptic responsive elements would include those that contribute to high BHRS-P and BPRS ratings and poor CPT performance, and are, at least in part, measurable as the functional activities of the biological substrata of sustained attention, e.g., the right midprefrontal cortex. While favorable clinical response was associated with effective resolution of the attentional deficit in the Kay and Singh study (Kay and Singh 1979), it is clear that there frequently remain aspects of attention and other important symptoms that are still abnormal following neuroleptic treatment.

\section{Conclusions}

In summary, our findings that treatment-resistant schizophrenics demonstrate frontal hypometabolism in the presence of striatal hyperactivity is very similar to the data reported by two other groups working with schizophrenic patients who had never received neuroleptics before (Biver et al. 1995; Rubin et al. 1991). Rubin et al. (1991) interpreted their results, obtained while patients performed the Wisconsin Card Sort, as suggestive of impaired striatal suppression on the left side. The requirements of CPT are also associated with suppression of "quieting" of a number of brain regions including the basal ganglia and mid-cingulate. Thus, our data contains an element that can be viewed as evidence that a disconnection between the frontal cortex and other brain regions, e.g., the striatum (Buchsbaum et al. 1992a; Robbins 1990) and temporal lobe (Friston and Frith 1995), is responsible for the symptoms of schizophrenia. However, the case would be stronger were there abnormally high activities in these regions in the presence of normal prefrontal cortex activity, were there not an inverse correlation between striatal activity and symptoms, and were it not for the fact that neuroleptics increase striatal activity rather than quiet it.

The current data show that pre-treatment metabolic rates of brain regions that are part of the attention network are informative with respect to neuroleptic response prediction. Most notably abnormally low CRAF in a schizophrenic patient is predictive of a good antipsychotic response to clozapine or fluphenazine, whereas relatively high basal ganglia and low mid-cingulate activities are associated with poor treatment response. These findings imply that the sustained attention pathway and its distributed network of brain structures play an important role in the expression of psychotic symptoms and the mediation of response to antipsychotics.

\section{REFERENCES}

Andreasen NC (1984): Scale for the Assessment of Negative Symptoms (SANS). Iowa City, University of Iowa 
Andreason PJ, Zametkin AJ, Guo AC, Baldwin P, Cohen RM (1994): Gender related differences in regional cerebral glucose metabolism in normal volunteers. Psychiatr Res 51:175-183

Biver F, Goldman S, Luxen A, Delvenne B, De Maertelaer V, De La Fuente J, Mendelwicz J, Lostra F (1995): Altered frontostriatal relationship in unmedicated schizophrenic patients. Psychiatry Res 61:161-171

Brooks RA (1982): Alternative formula for glucose utilization using labeled deoxyglucose. J Nucl Med 23:538-539

Buchsbaum MS, Nuechterlein KH, Haier RJ, Wu J, Sicotte N, Hazlett E, Asarnow R, Potkin S, Guich S, Lagunas-Solar M (1990): Glucose metabolic rate in normals and schizophrenics during the continuous performance test assessed by positron emission tomography. Br J Psychiatr 156: 216-227

Buchsbaum MS, Haier RJ, Potkin SG, Neuchterlein K, Bracha S, Jerabek P, Trenary J, Tafalla R, Reynolds C, Bunney WE (1992a): Frontostriatal disorder of cerebral metabolism in never-medicated schizophrenics. Arch Gen Psychiatr 49:935-942

Buchsbaum MS, Potkin SG, Marshall JF, Lotterberg S, Teng C, Heh C, Tafalla R, Reynolds C, Abel L, Plon L, Bunney WE (1992b): Effects of clozapine and thiothixene on glucose metabolic rate in schizophrenia. Neuropsychopharmacology 6:155-163

Buchsbaum MS, Potkin SG, Siegel BV, Lohr J, Katz M, Gottschalk LA, Gulasekaram B, Marshall JF, Lottenberg S, Teng CY, Abel L, Plon L, Bunney WE (1992c): Striatal metabolic rate and clinical response to neuroleptics in schizophrenia. Arch Gen Psychiatr 49:966-974

Buchsbaum MS (1995): Positron emission tomography studies of abnormal glucose metabolism in schizophrenic illness. Clin Neurosci 3:122-130

Bunney WE Jr, Hamburg DA (1963): Methods for reliable longitudinal observation of behavior. Arch Gen Psychiatr 9:280-294

Clark C, Carson R, Kessler R, Margolin R, Buchsbaum M, DeLisi L, King C, Cohen R (1984): Alternative statistical models for the examination of clinical positron emission tomography/fluorodeoxyglucose data. J Cereb Blood Flow Metab 5:142-150

Cohen RM, Semple WE, Gros M (1986): Positron emission tomography. Psychiatric Clin North Am 9:65-79

Cohen RM, Semple WE, Gross M, Nordahl TE, DeLisi LE, Holcomb HH, King AC, Morihisa JM, Pickar D (1987): Dysfunction in a prefrontal substrate of sustained attention in schizophrenia. Life Sci 40:2031-2039

Cohen RM, Semple WE, Gross M, Nordahl TE (1988a): From syndrome to illness: Delineating the pathophysiology of schizophrenia with PET. Schizophr Bull 14:169-176

Cohen RM, Semple WE, Gross M, Nordahl TE, Holcomb HH, Dowling MS, Pickar D (1988b): The effect of neuroleptics on dysfunction in a prefrontal substrate of sustained attention in schizophrenia. Life Sci 43:1141-1150

Cohen RM, Semple WE, Gros M, Holcomb HH, Dowling MS, Nordahl TE (1988c): Functional localization of sustained attention: Comparison to sensory stimulation in the absence of instruction. Neuropsychiatr Neuropsychol Behav Neurol 1:3-20

Cohen RM, Semple WE, Gross M, King AC, Nordahl TE
(1992): The metabolic brain pattern of sustained auditory discrimination. Exp Brain Res 92:165-172

Cohen RM, Gross M, Semple WE, Nordahl TE, Sunderland T (1994): The metabolic brain pattern of young subjects given scopolamine. Exp Brain Res 100:133-143

Cohen RM, Nordahl TE, Semple WE, Andreason P, Litman RE, Pickar D (1997): The brain metabolic patterns of clozapine- and fluphenazine-treated schizophrenic patients during a continuous performance task. Arch Gen Psychiatr 54:481-486

DeLisi LE, Holcomb HH, R.M. C, Pickar D, Carpenter W, Morihisa JM, King AC, Kessler R, Buchsbaum MS (1985): Positron emission tomography in schizophrenic patients with and without neuroleptic medication. J Cereb Blood Flow Metab 5:201-206

Early TS, Reiman EM, Raichle ME, Spitznagel EL (1987): Left globus pallidus abnormality in never-medicated patients with schizophrenia. Proc Natl Acad Sci USA 84:561-563

Erlenmeyer-Kimling L, Cornblatt B (1987): The New York High-Risk Project: A follow up report. Schizophr Bull 13:451-461

Friston KJ, Frith CD (1995): Schizophrenia: A disconnection syndrome? Clin Neurosci 3:89-97

Kane J, Honigfeld G, Singer J, Meltzer H (1988): Clozapine for the treatment-resistant schizophrenic. A doubleblind comparison with chlorpromazine. Arch Gen Psychiatr 45:789-796

Kay SR, Singh MM (1979): Cognitive abnormality in schizophrenia: A dual-process model. Biol Psych 14:155-176

Levy DL (1996): Location, location, location: The pathway from behavior to brain locus in schizophrenia. In Matthysse S, Levy DL, Kagan J, Benes FM (eds), Psychopathology: The Evolving Science of Mental Disorder. Cambridge, UK, Cambridge University Press, pp 100-126

Matochik JA, Zametkin AJ, Cohen RM, Hauser P, Weintraub BD (1996): Abnormalities in sustained attention and anterior cingulate metabolism in subjects with resistance to thyroid hormone. Br Res 723:23-28

Matsui T, Hirano A (1978): An Atlas of the Human Brain for Computerized Tomograph. New York, Igaku-Shoin Medical

Mesulam M-M (1981): A cortical network for directed attention and unilateral neglect. Ann Neurol 10:309-325

Nuechterlein KH (1991): Vigilance in schizophrenia and related disorders. In Steinhauer SR, Gruzelier JH, Zubin J (eds), Handbook of Schizophrenia, Vol 5: Neuropsychology, Psychophathology and Information Processing. New York, Elsevier Science Publishers B.V., pp 397433

Nuechterlein KH, Buchsbaum MS, Dawson ME (1994): Neuropsychological vulnerability to schizophrenia. In David AS, Cutting JS (eds), The Neuropsychology of Schizophrenia. Hillsdale, USA, Lawrence Erlbaum Assoc

Overall JE, Gorham DE (1961): The brief psychiatric rating scale. Psychol Res 10:799-812

Phelps ME, Huang S-C, Hoffman EJ, Selin C, Sokoloff L, Kuhl DE (1979): Tomographic measurement of local cerebral glucose metabolic rate in humans with [F-18]1fluro-2-deoxy-D-glucose: Validation of method. Ann Neurol 6:371-388 
Pickar D, Owen RR, Litman RE, Konicki PE, Gutierrez R, Rapaport MH (1992): Clinical and biologic response to clozapine in patients with schizophrenia: Crossover comparison with fluphenazine. Arch Gen Psychiatr 49:345-353

Posner MI, Petersen SE (1990): The attention system of the human brain. Annu Rev Neurosci 13:25-42

Resnick SM, Gur RE, Alavi A, Gur RC, Reivich M (1988): Positron emission tomography and subcortical glucose metabolism in schizophrenia. Psychiatr Res 24:1-11

Robbins TW (1990): The case for fronto-striatal dysfunction in schizophrenia. Schizophr Bull 16:391-402

Rubin P, Holm S, Friberg L, Videbech P, Andersen HS, Bendsen B, Stromso N, Larsen JK, Lassen N, Hemmingsen R (1991): Altered modulation of prefrontal and subcortical brain activity in newly diagnosed schizophrenia and schizophreniform disorder: A regional cerebral blood flow study. Arch Gen Psychiatr 48:987-995

Semple WE, Johnson JL, Cohen R (1993): Reliability in positron emission tomography. In London ED (ed), Imaging Drug Action in the Brain. Boca Raton, CRC Press, pp 297-316

Sokoloff L, Reivich M, Kennedy C, DesRosiers MH, Patlak
CS, Pettigrew KD, Sakurada O, Shinohara M (1977): The [14-C]deoxyglucose method for the determination of local cerebral glucose utilization: Theory, procedure, and normal values in the conscious and anesthetized albino rat. J Neurochem 28:897-916

Tamminga CA, Thaker GK, Buchanan R, Kirkpatrick B, Alphs LD, Chase TN, Carpenter WT (1992): Limbic system abnormalities identified in schizophrenia using positron emission tomography with fluordeoxyglucose and neocortical alterations with deficit syndrome. Arch Gen Psychiatr 49:522-530

Weinberger DR, Berman KF, Zec RF (1986): Physiological dysfunction of dorsolateral prefrontal cortex in schizophrenia: I. Regional cerebral blood flow. Arch Gen Psychiatr 43:114-124

Wolkin A, Jaeger J, Brodie JD, Wolf AP, Fowler J, Retrosen J, Gomez-Mont F, Cancro R (1985): Persistence of cerebral metabolic abnormalities in chronic schizophrenia as determined by positron emission tomography. Am J Psychiatr 142:564-571

Wolkin A, Sanfilipo M, Wolf AP, Angrist B, Brodie J, Rotrosen J (1992): Negative symptoms and hypofrontality in chronic schizophrenia. Arch Gen Psychiatr 49:959965 